\title{
AUTOMATIC SYSTEM FOR ACQUISITION AND MONITORING OF ECG SIGNALS IN THE DIAGNOSIS OF PATHOLOGIES FREQUENT
}

\section{SANTIAGO RUBIÑOS, JUAN GRADOS, WILVER AUCCAHUASI, EDWIN HUARCAYA, RAÚL HINOJOSA, JESSICA MEZA, JOSHUA MAYTA, KEVIN SEDANO}

Facultad de Ingeniería Eléctrica y Electrónica, Universidad Nacional del Callao, Lima, Perú

\begin{abstract}
With the objective to make a possible diagnosis of cardiac pathologies, an automatic system was designed that monitors the electrocardiogram (ECG) signals of the patient in real time to relate parameters to a database, which has recorded different types of simulated pathologies in Lab View. This will be used to prevent cardiovascular diseases (CVDs). Electrodes and the AD8232 ECG sensor were used to amplify, filter and reduce the noise of the signal acquired from the patient. The information was sent to an Arduino for the communication via serial port to the LabView software where the possible diagnosis will be generated.

KEYWORDS: ECG Signal, Pathologies, Filters, Cardiovascular Diseases, Lab View
\end{abstract}

Received: Jun 08, 2020; Accepted: Jun 28, 2020; Published: Sep 05, 2020; Paper Id.: IJMPERDJUN20201079

\section{INTRODUCTION}

The electrocardiogram is the graphic representation of the recording of electrical activity generated by the heart. I know performs a non-invasive procedure using electrodes to get the signal from the body surface. The sum of all the action potentials of the myocardial fibers form the QRS complex, which is the resulting graph in said exam. In people who do not present anatomical alterations or functional, electrical impulses propagate to a uniform speed longitudinally and transversely. Yes, this was not the case, the electrophysiological properties they vary, being different from those of a healthy myocardium. [1]

These signals can be digitized in order to treat them using algorithms on devices like microcontrollers or DSPs. [2]

To understand the relationship between the electrical events of the heart and electrocardiographic leads are assumed three premises:

- The points on the body surface are equidistant to the center of the heart.

- The conductive medium of the electrical impulse is formed by the tissues and structures between the heart and the surface of the skin, and have the property of homogeneous driving.

- The electromotive forces that are caused in the heart generate a large dipole that creates electric fields they are symmetrically distributed in the conductive medium. [3]

- The instruments with which the electrocardiograms is the electrocardiograph. Which is It consists of four blocks which are: Amplifier, Galvanometer, Registration System and System Calibration. 
- The electrical signal collected by the electrodes placed on the body surface, it is sent to an amplifier for better signal treatment. Then the galvanometer receives the signal from the amplifier and through a circuit oscillating, the movement of the recording needle occurs print the electric current on graph paper. He electrocardiograph has a calibration and filtering system signals provided by the guarantee of an electrical signal without interference. It also allows calibration and standardization of the electrocardiogram, so that, for example, an electric potential of $1 \mathrm{mV}$ is transcribed by the needle movement at $1 \mathrm{~cm}$. [4]

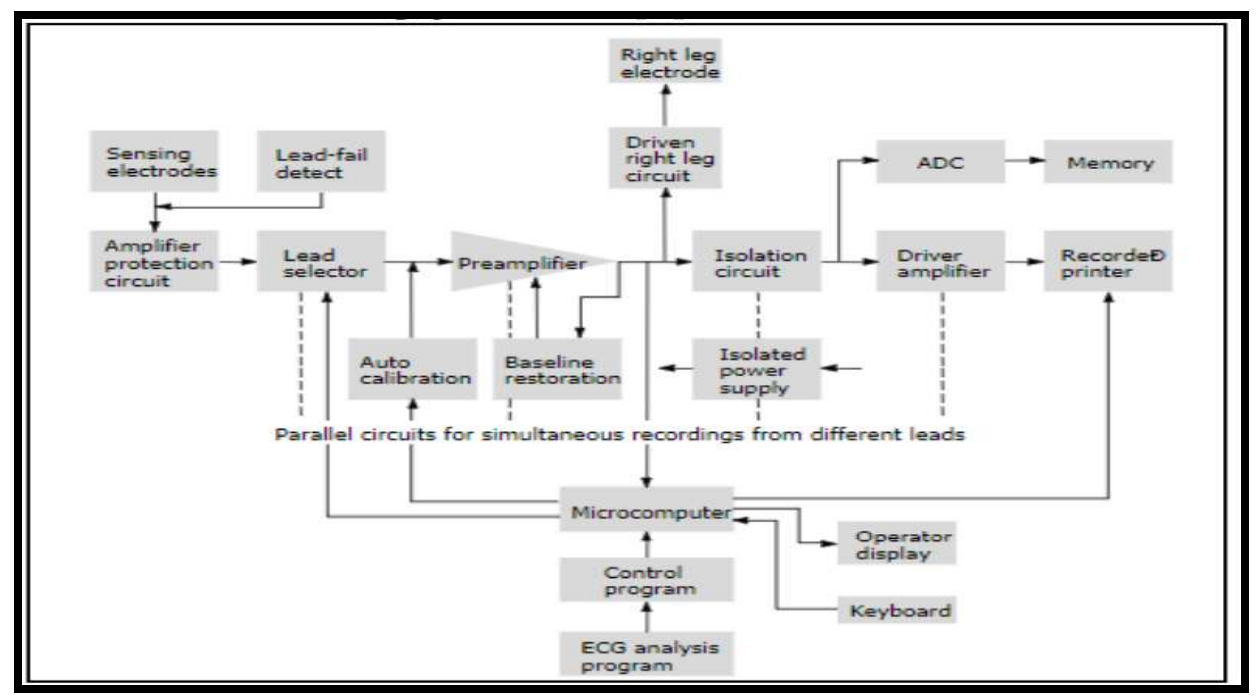

Figure 1: Block Diagram of an Electrocardiograph.

\section{CARDIOVASCULAR DISEASES}

\section{Vascular Brain Accident}

It is a medical emergency, second cause of death and the third leading cause of disability in the world, its Mortality is up to $85 \%$ of cases. Extracted data of the electrocardiogram as the variability of the frequency cardiac, variability of the QT interval, dispersion of the QT interval lead to the conclusion that an alteration in the functioning of the autonomic nervous system can result in the appearance of cardiac dysfunction and therefore cause two death. For this reason, the study of electrocardiographic records. [5]

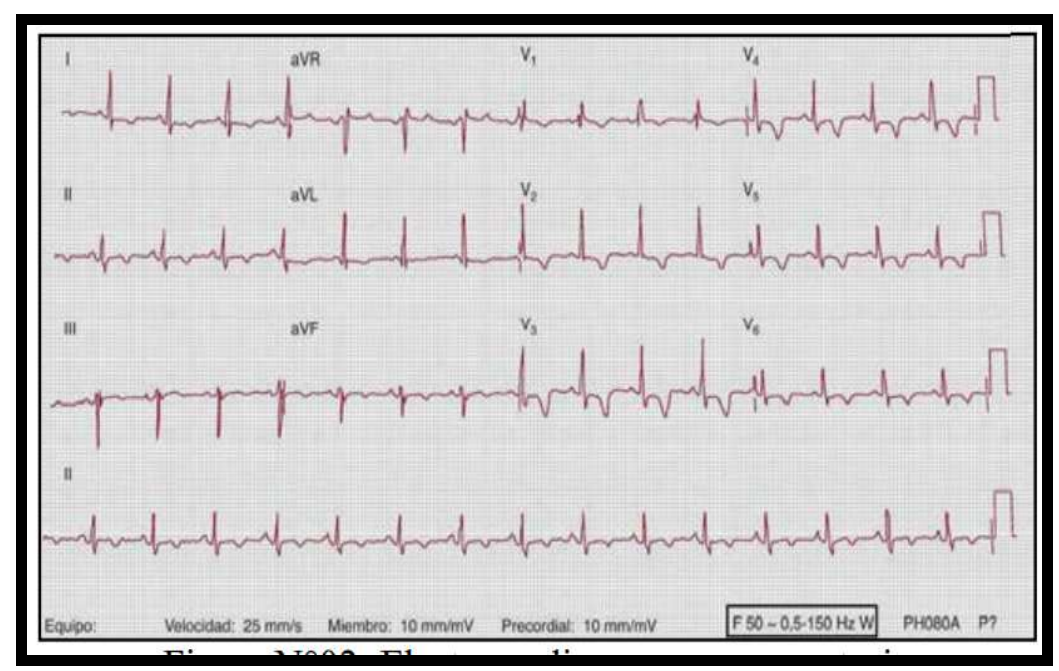

Figure 2: Preoperative Electrocardiogram. 


\section{Sudden Cardiac Death}

It is a sudden cardiac arrest secondary to arrhythmias cardiac. The highest number of victims occurs in people between 45 to 75 years of age. The main cause is coronary artery disease with or without heart attack myocardium. $30 \%$ or $40 \%$ of cases are people with others types of heart disease such as: Cardiomyopathy dilated, hypertrophic, infiltrative. In adults aged 35 to less, the causes can be: Hypertrophic cardiomyopathy, primary arrhythmic diseases such as long QT syndrome, short QT syndrome, early repolarization and arrhythmogenic dysplasia of the ventricle right. The greatest number of sudden cardiac arrests occurs by arrhythmias type PV and TV. Cardiac arrest treatment sudden secondary to these arrhythmias is defibrillation ventricular, the first minute the success of this procedure is higher than $90 \%$ and drops $7-10 \%$ per minute without cardiopulmonary resuscitation (CPR) and with CPR descends 3-4\% per minute. [6]

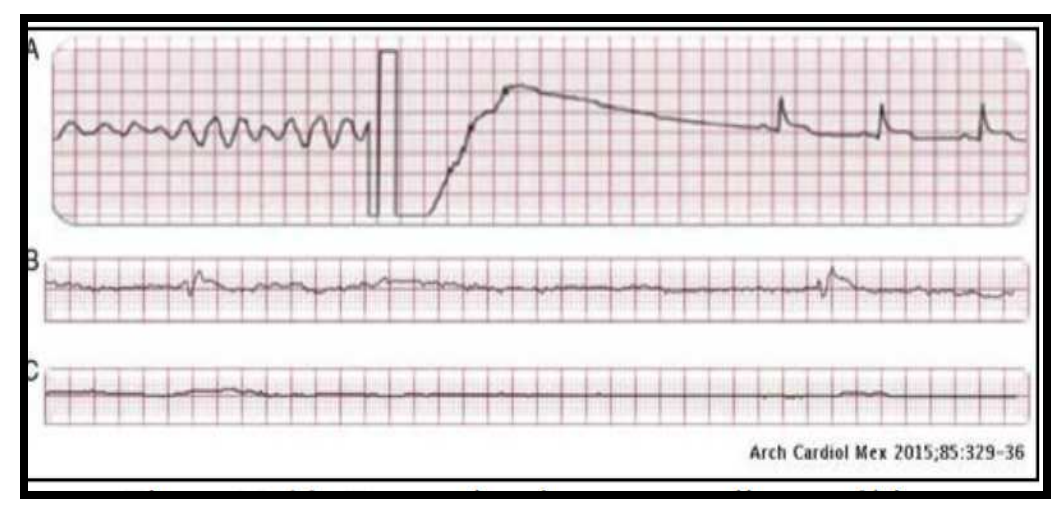

Figure 3: Sudden Cardiac Arrest Scenarios.

\section{Cardiac Arrhythmias}

It is an alteration of the heart rate which presents in the form of tachycardia or bradycardia, or with a rhythm irregular heart. Its causes can be problems systematic, structural problems of the myocardium, or without after cardiac pathology. [7]

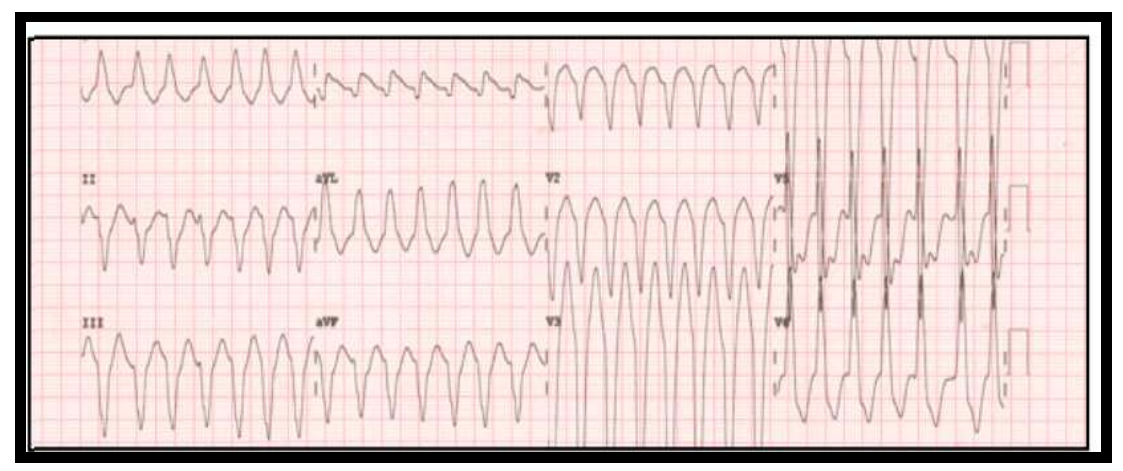

Figure 4: ECG Arrhythmia.

\section{Theoretical Framework A}

\section{ECG Signal}

They are a series of two-dimensional waves, where the axis of ordinate represents the magnitude of voltage (mV) and the axis of the abscissa represents the magnitude of time (ms). The waves that make up the set of ECG signals are: 


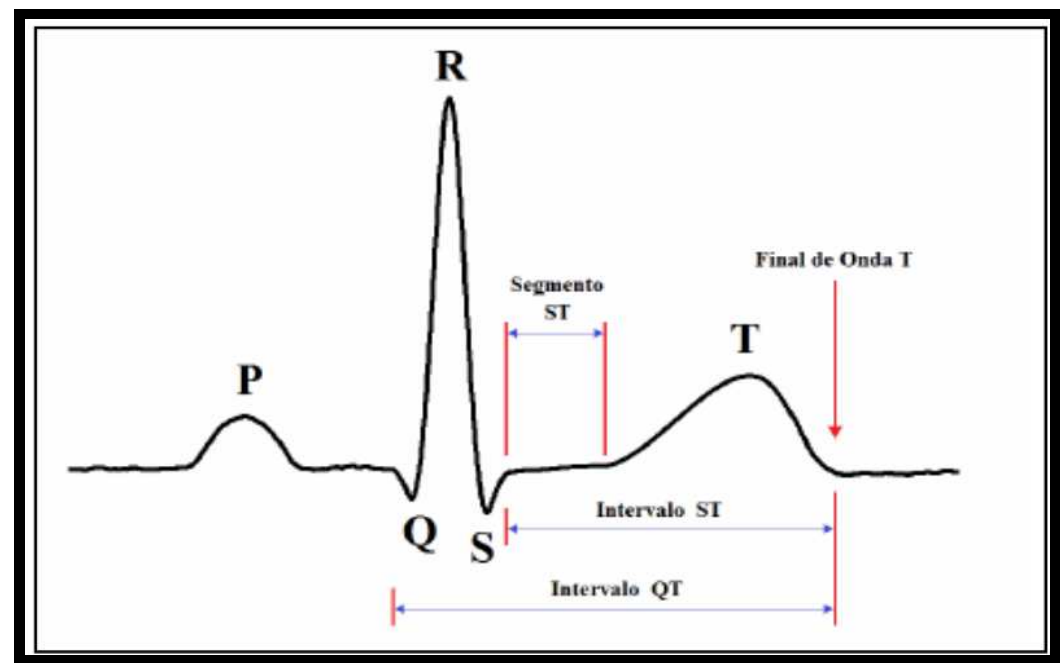

Figure 5: ECG Signal and its Intervals.

\section{P Wave}

Wave generated by atrial depolarization. In its sinus state, it has a rounded shape, its amplitude is $0.25 \mathrm{mV}$, and lasts for $100 \mathrm{~ms}$.

\section{PQ Interval}

Time interval from the start of the $\mathrm{P}$ wave to the QRS complex, is translated as the time of conduction from atrial excitation to onset of ventricular depolarization. It is a frequency dependent interval, so in a tachycardia, the heart rate is higher, then the PQ segment is shorter, and in the case of a bradycardia, where the heart rate is smaller, the PQ segment is longer. It ranges from $120 \mathrm{~ms}$ to $200 \mathrm{~ms}$.

\section{QRS Complex}

Indicates rapid, custom ventricular depolarization that the action potential spreads through the contractile ventricular fibers. Start with the $\mathrm{Q}$ wave, which is a negative deflection, next to this, the $\mathrm{R}$ wave is presented, which has a triangular shape and a positive peak, and ends with a negative $S$ wave. Under normal conditions, this complex has a duration less than $100 \mathrm{~ms}$, the $\mathrm{R}$ wave has a voltage not greater than $3.5 \mathrm{mV}$ and the $\mathrm{S}$ wave has a period less than $60 \mathrm{~ms}$.

\section{S-T Segment}

It covers from the end of the $\mathrm{S}$ wave to the beginning of the $\mathrm{T}$ wave, indicates the time in which the fibers Contractile ventricles are depolarized.

\section{Q-T Interval}

It includes from the beginning of the $\mathrm{Q}$ wave, until $\mathrm{T}$ wave ends. Indicates the time elapsed since the onset of ventricular depolarization until repolarization of said ventricle.

\section{T Wave}

It is caused by the relaxation of the ventricles and indicates ventricular repolarization. It is shown like a positive deflection, it's smaller and more wider than the QRS complex because the repolarization occurs more slowly than depolarization. 


\section{U Wave}

It is not too often that it is represented in a ECG. [8]

\section{MATERIALS AND METHODS}

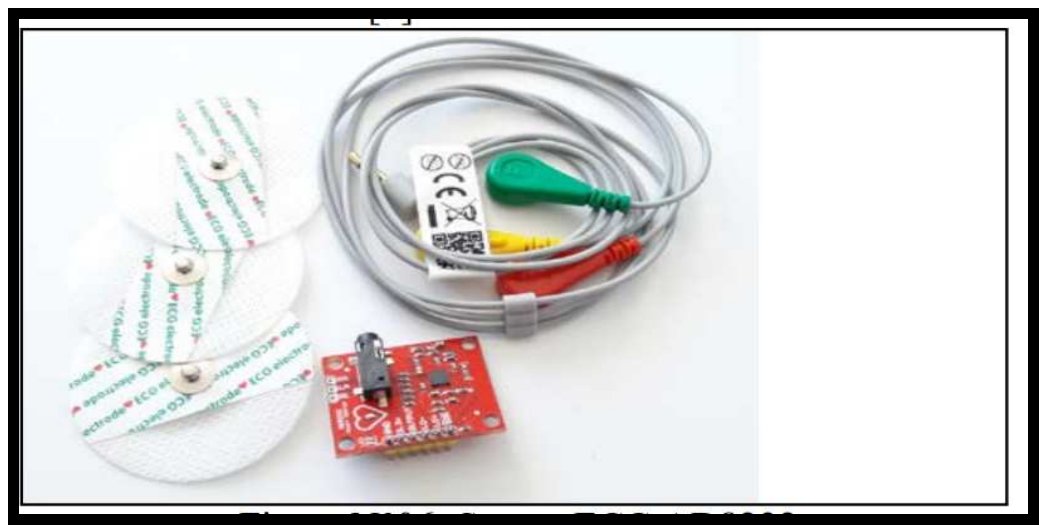

Figure 6: AD8232 ECG Sensor.

\section{Sensing the ECG Signals}

To obtain the ECG signals we will use the module AD8232 that allows obtaining the electrical activities of the heart. The AD8232 instrumentation amplifier has the easy to apply gain and filter near signals CC simultaneously. [9]

\section{Signal Conditioning}

Adequate signal conditioning for obtaining of the ECG, is constituted by an instrumental amplifier that is essential in the signal acquisition process because does not allow the addition of high frequency components that may cause aliasing in the signals. The conditioning system is intended to amplify and limit the bandwidth of the ECG signal to be acquired. In addition to the amplification stage, it is necessary to make use of stages containing analog filter. Filtering will help us removing noise signals and will allow a better process in analog to digital conversion. [2]

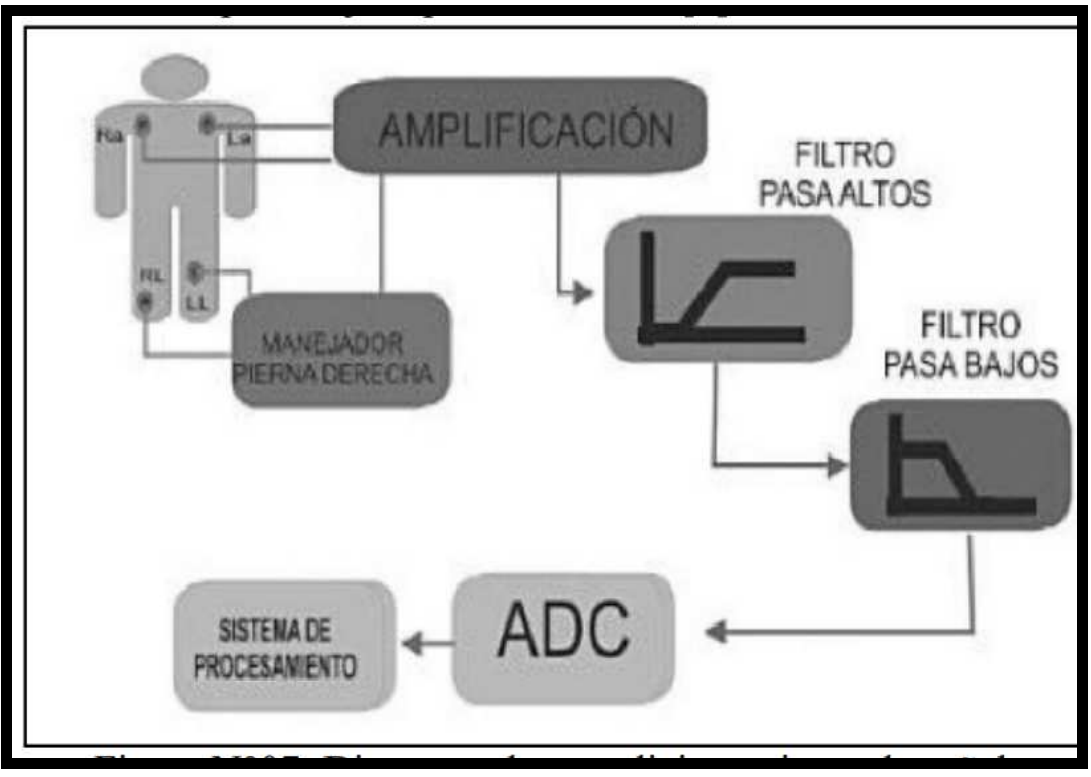

Figure 7: Signal Conditioning Diagram. 
Below is the proper settings to perform a heart monitor setup, for the obtaining the ECG signal with minimal distortion, the AD8232 It is designed with a $0.5 \mathrm{~Hz}$ high pass filter followed by a $40 \mathrm{~Hz}$ bipolar low-pass filter. [9]

\section{Arduino}

The Arduino is based on a microcontroller from the manufacturer Atmel, it is considered as a range of circuits open source electronic. This device allows the simplification in order for everyone to have opportunity to perform device programming interactive. [10]

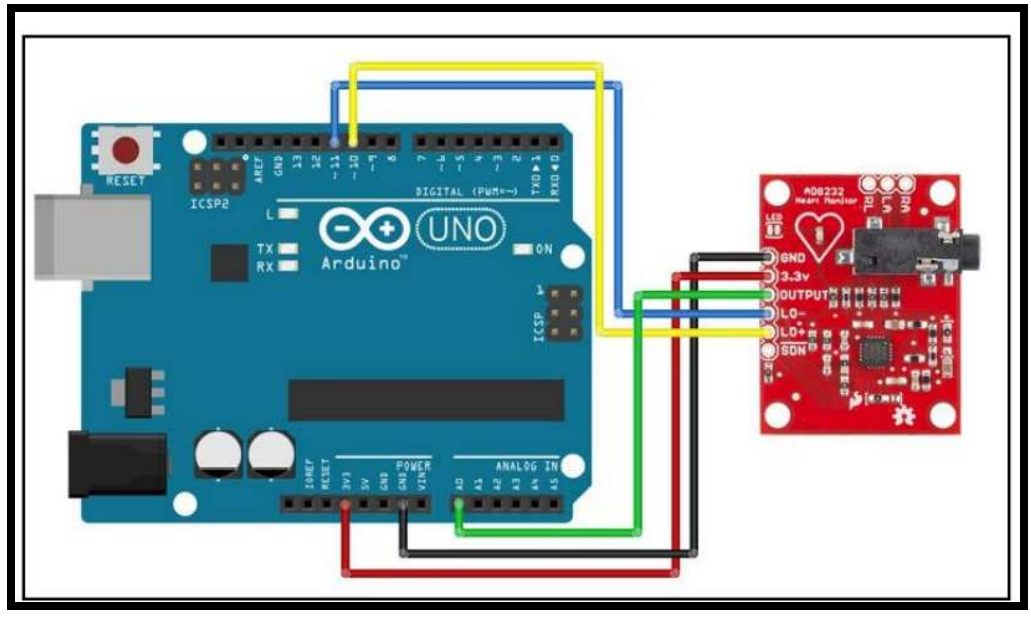

Figure 8: Arduino Development Board.

\section{Serial Communication}

It is a widely used way that helps us communicate electronics devices. Through communication we can send and receive data from the computer to Arduino. The Arduino configuration for the use of the Serial communication can be in Simplex, Duplex or Full Duplex.

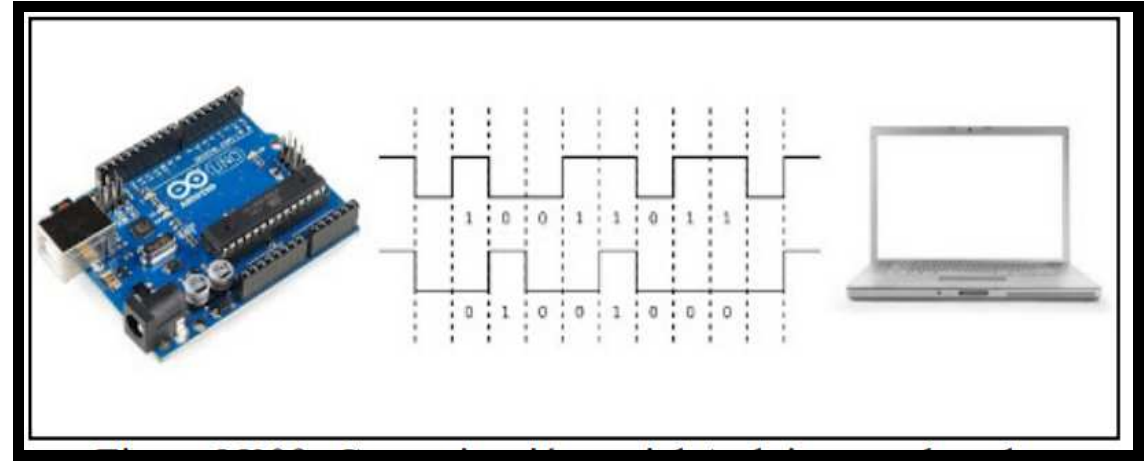

Figure 9: Arduino Serial Communication - Computer.

\section{LabView Software}

It is a graphic programming language designed to scientists and engineers. With a career over 20 years under development, is a software that allows interactive and personalized automation. [11] 


\section{Low Pass Filter}

This filter is responsible for discriminating between frequencies ranging from zero to the cutoff frequency. To the set of frequencies that are delimited by the frequency of cut is called a through band, while frequencies above this cutoff frequency are called band removed. [12]

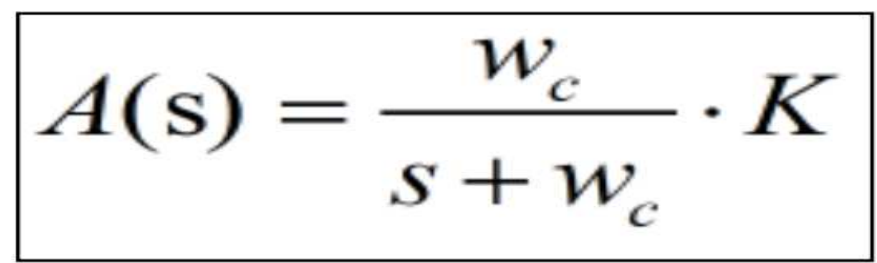

Figure 10: Low Pass Filter Transfer Equation First Order.

$$
A(\mathrm{~s})=\frac{w_{c}^{2}}{s^{2}+\frac{w_{c}}{Q} s+w_{c}^{2}} \cdot K
$$

Figure 11: Low Pass Filter Transfer Equation Second Order.

\section{Band Pass Filter}

It has a higher and lower cutoff frequency. The passband is between the cutoff frequencies upper and lower. The rejection band is from zero to the lower cutoff frequency and from the frequency superior cut to infinity. This filter is always second order since a bandpass filter is combined with one passes high. [12]

$$
\mathrm{A}(\mathrm{s})=\frac{\frac{w_{c}}{Q} \cdot S}{s^{2}+\frac{w_{c}}{Q} \cdot s+w_{c}^{2}} \cdot K
$$

Figure 12: Band Pass Filter Transfer Equation.

\section{Developing}

The analysis of three common pathologies in people, which are: Ventricular Tachycardia, Tachycardia Supraventricular and Bradycardia.

We use the AD8232 sensor to capture the impulses the heart by means of electrodes placed on the body surface. This signal is sent to a circuit amplifier and then to a microcontroller which in this case is an Arduino UNO. Through serial communication we transfer data from the microcontroller to the computer to that these can be treated in the LabView software. 


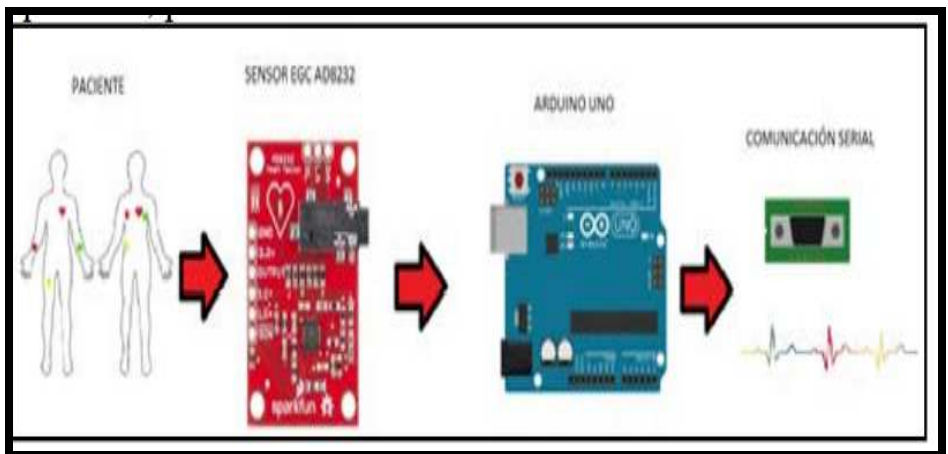

Figure 13: Complete System Diagram.

Through a series of algorithms in LabView using the tools that this software has, we can determine whether or not a person has these conditions.

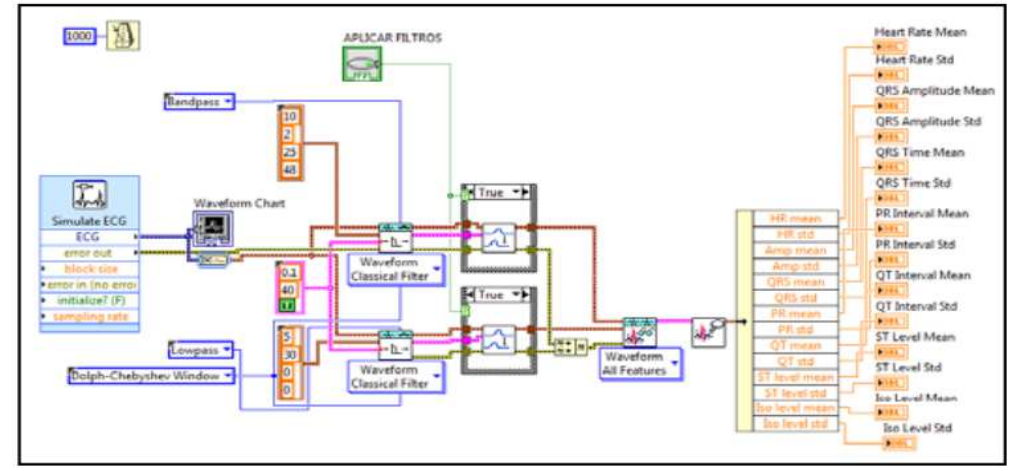

Figure: 14 ECG Signal Generator Circuit.

In order to obtain different ECG signals, we made use of NI Biomedical Toolkit, which not only allowed to generate the signals, but also analyze different parameters such as heart rate or the QRS complex. At the same time we use low pass filters and band pass filters to accommodate these signals. Below is the experience to obtain the different cases:

We proceed to make conditional circuits with the parameters investigated, so that we can make a possible diagnosis of a pathology indicator with the data obtained from the ECG signal.

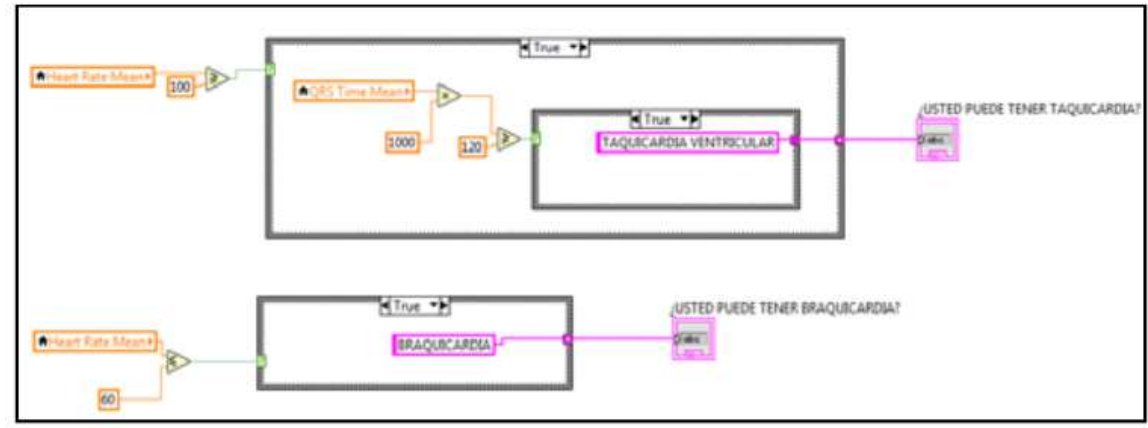

Figure 15: Conditional Circuit for Diagnosis of Indicators. 


\section{RESULTS}

In the case of a person with Tachycardia Ventricular, the values of its QRS complex are displayed, PR interval, QT interval. You are told the diagnosis and you shows the ECG waveform you have.

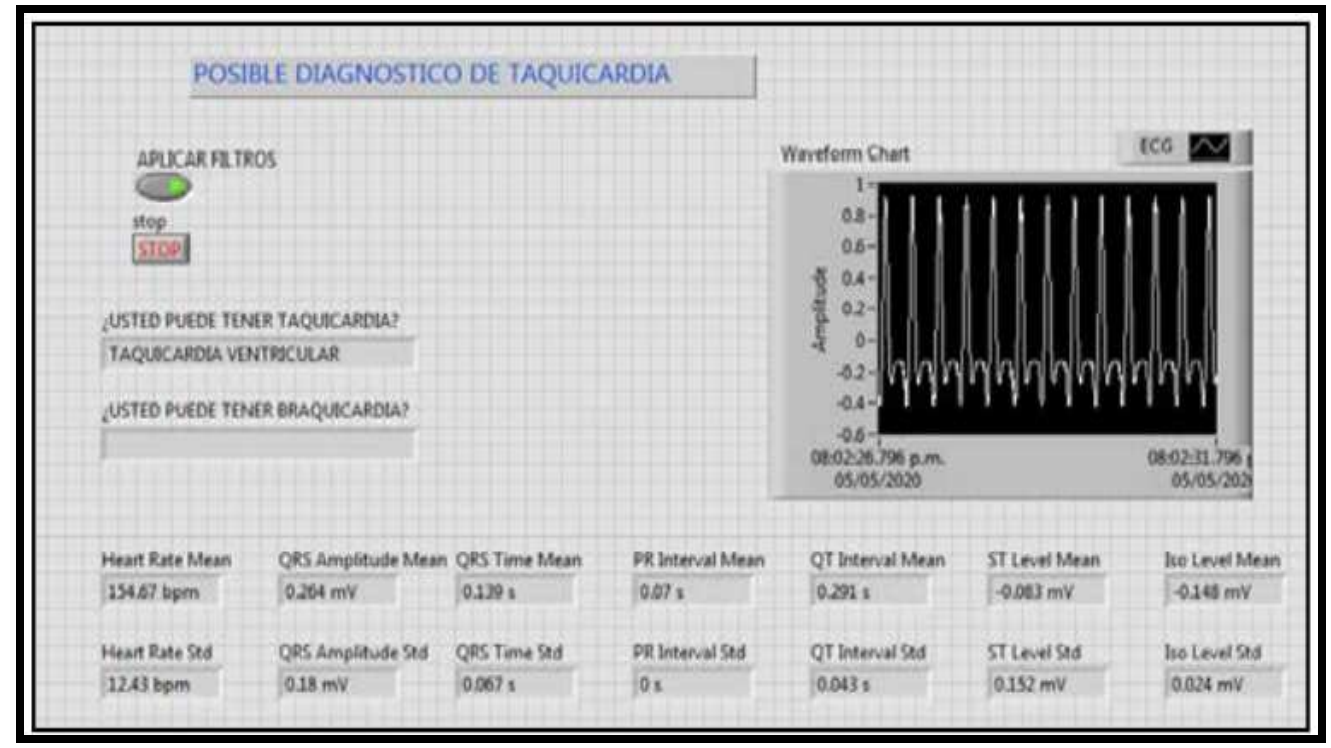

Figure 16: Ventricular Tachycardia Screen Result.

In the case of a person presenting Bradycardia, show the values of your QRS complex, PR interval, QT interval. The diagnosis is told and the form is shown of ECG wave you have.

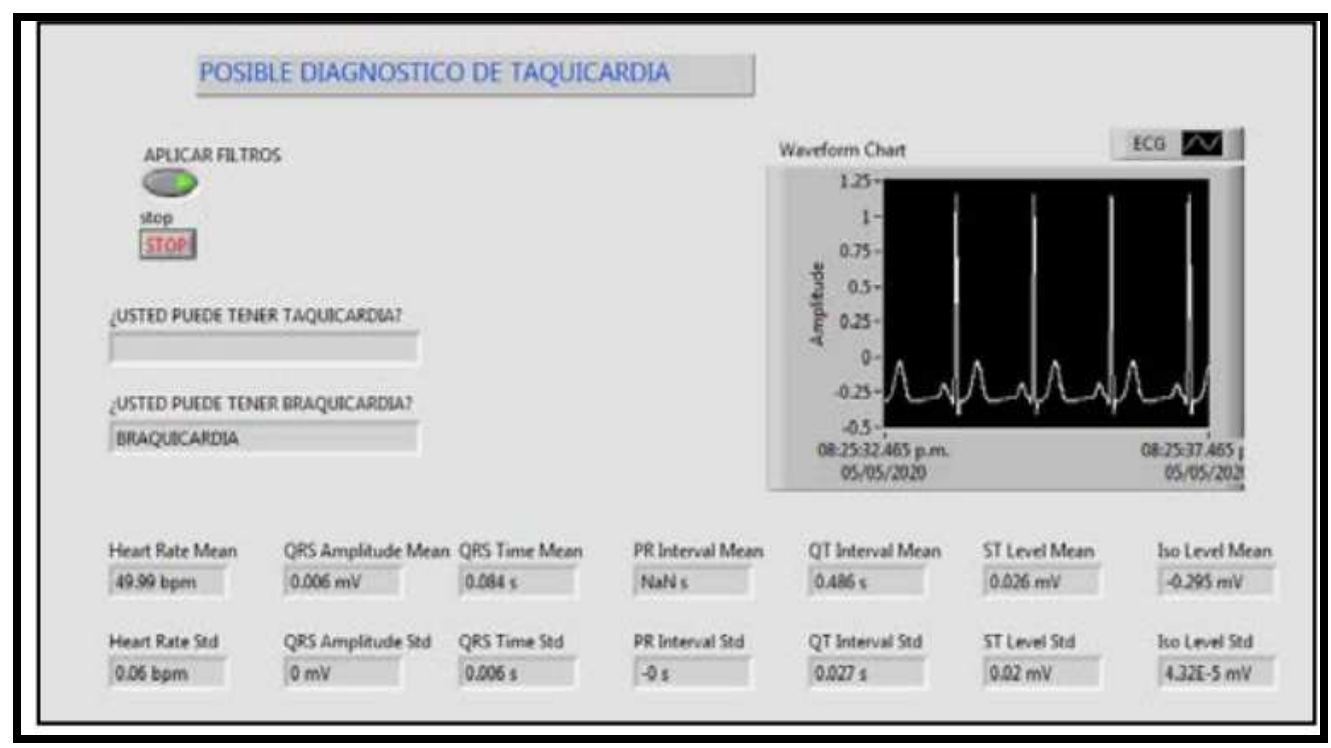

Figure 17: On-Screen Result of Bradycardia.

If you want to do further analysis of the data and get more possible diagnoses you can 


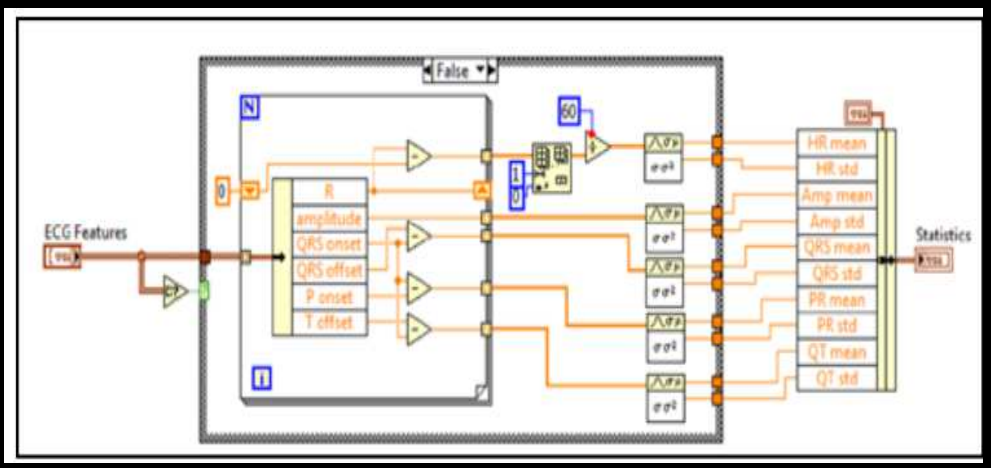

Figure 18: Statistical Analysis of the Characteristics Extracted from the ECG by LabView.

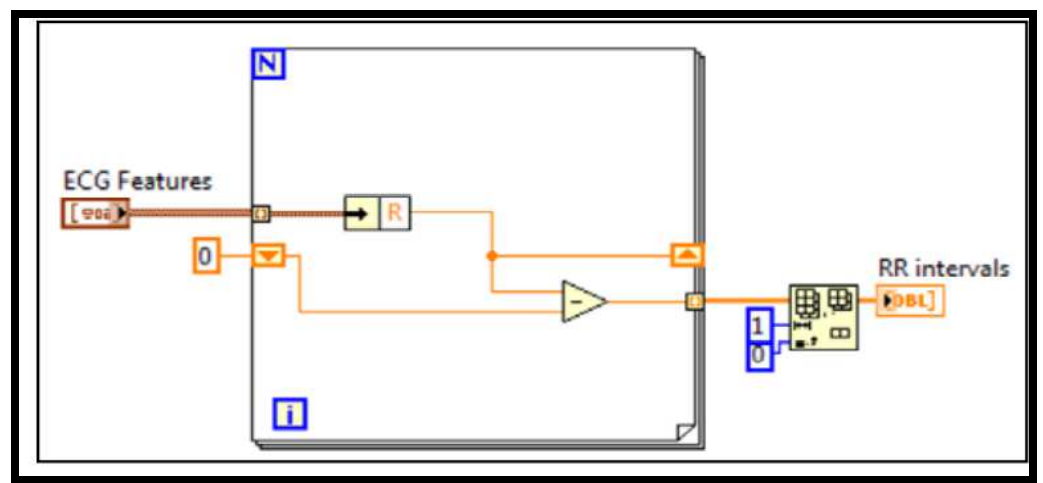

Figure 19: Obtaining the RR Intervals of the ECG Characteristics by Subtracting the Adjacent R Positions By Labview.

\section{CONCLUSIONS}

The potential difference caused by impulses electrical of the heart can be picked up by the sensor AD8232 and monitored in LabView using a controller and COM port as communication bridge between the patient and the computer.

Indicators of major pathologies such as arrhythmias, Blockages, AVC, can be diagnosed early with algorithms built in the LabView Software. The tools for Low Pass and Band Pass filters that provides LabView, helps filter the signal from the ECG simulator.

The LabView Software helped us with obtaining parameters like heart rate and QRS width but are not the only parameters that can be achieved and add. In a future project as the parameters you can increase the amount of diagnostics possible

\section{REFERENCES}

1. O. Gutiérrez, «El electrocardiograma de alta resolución,» Revista Costarricense de Cardiología, vol. 3, nº 2, pp. 48-53, 2001.

2. J. González Barajas, Electrocardiográma desde una visión digital, Bogotá: Universidad Santo Tomás, 2016.

3. G. Pozas Garza, «El electrocardiograma normal,» Avances, vol. 8, $n^{\circ}$ 25, pp. 35-39, 2011.

4. C. Castellano y F. Attie, Electrocardiograma Clínica, Madrid: Elsevier España, 2004. 
5. O. L. Rueda Ochoa, H. A. Torres Mantilla, C. A. Fernández Dulcey, M. M. Villa Acuña, S. T. Velasco Gómez, C. A. Niño Niño y D. A. Sierra Bueno, «Factores clínicos y electrocardiográficos como predictores de mortalidad en pacientes en fase aguda de un primer evento cerebrovascular,» Revista de la Universidad Industrial de Santander. Salud, vol. 46, $n^{\circ} 2$, pp. 147- 158, 2014 .

6. H. Rodríguez Reyes, M. Muñoz Gutiérrez, M. F. Márquez, G. Pozas Garza, E. Asensio Lafuente, F. Ortiz Galván, S. Lara Vaca y V. A. Mariona Montero, «Muerte súbita cardiaca. Estratificación de riesgo, prevención y tratamiento,» Archivos de cardiología de México, vol. 85, nº 4, pp. 329-336, 2015.

7. C. V. Esparza Guanuche, J. A. García Maldonado, E. Y. Reyes Rueda y L. García Bastidas, «Manejo de las arritmias cardiacas en las unidades de primer nivel de salud,» Polo del Conocimiento, vol. 4, nº 10, pp. 118- 135, 2019.

8. S. Hurtado Requena, Artist, Diseño y montaje de un simulador ECG. [Art]. Universidad de Málaga, 2018.

9. Analog Device, Datasheet: AD8232, 2012.

10. N. Goilav y G. Loi, Arduino: Aprender a desarrollar para crear objetos inteligentes, Barcelona: ENI, 2016.

11. M. Schwartz y O. Manickum, Programming Arduino with LabView, Birmingham: Packt Publishing, 2015.

12. E. M. Balboa Morales y M. A. Sáez Saldías, Artists, Análisis, Diseño y Construcción de Filtros Activos. [Art]. Universidad Del Bío-Bío, 2016. 


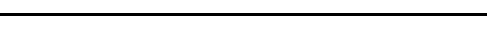

